\title{
Managing surge staff and resources at the WHO Representative Office in the Philippines after Typhoon Haiyan
}

\author{
Rosemarie Urquico, ${ }^{a}$ Heleisha Racel Laviña, ${ }^{a}$ Megan Counahan ${ }^{a}$ and Julie Lyn Halla
}

Correspondence to Rosemarie Urquico (email: urquicor@wpro.who.int).

$\mathrm{T}$ he World Health Organization (WHO) Representative Office in the Philippines is accustomed to responding to disasters as the country is frequently hit by typhoons and earthquakes. ${ }^{1}$ Between 2009 and 2014 the Philippines was hit by 14 typhoons or tropical storms annually. ${ }^{2}$ WHO Representative Office in the Philippines works closely with and is located alongside the Department of Health $(\mathrm{DOH})$ in Metropolitan Manila. Together, they co-lead the humanitarian Health Cluster that provides immediate response and recovery support, technical expertise and capacity enhancement to manage all types of crises. WHO is guided by the Emergency Response Framework (ERF) with the ERF grading system guiding the extent, complexity and duration of WHO support and the required emergency standard operating procedures during responses, ranging from "ungraded" to "Level 3," the maximum level of response. ${ }^{3}$

Using the ERF system, Typhoon Haiyan was graded as a Level 3 emergency. ${ }^{4}$ Haiyan occurred one month after an ERF Grade 2 earthquake in Bohol where over 1.2 million people were affected and an estimated 79000 structures damaged, some irrevocably. ${ }^{5}$ An ERF Level 1 event was also ongoing as a result of a clash between the Moro National Liberation Front and the Armed Forces of the Philippines in September 2013 in what came to be known as the Zamboanga City crisis. ${ }^{6}$ In December 2012, the ERF Level $1^{7}$ Typhoon Bopha made landfall three times in Northern Mindanao, Central Visayas and Palawan. ${ }^{8}$

The objective of this paper is to compare the role of the administrative team from the WHO Representative Office in the Philippines in the response following
Typhoon Haiyan to the response with the three previous large-scale events, assess the lessons learnt and provide recommendations for managing future responses.

\section{METHODS}

The Global Management System (GSM) is an Oraclebased, enterprise-resource planning system that records business processes among all levels of $\mathrm{WHO}^{9}$ in areas of human resources, payroll, budget and finance, procurement, travel and programme management. Each GSM transaction requires a different level of approval from WHO staff. All transactions are processed by the Global Service Centre (GSC) located in Kuala Lumpur, Malaysia.

We assessed records from GSM on two core functions that have a direct effect on disaster responses - staff and consultant contracts and goods procurements. There are several administrative steps involved in contracting staff and consultants, which can vary depending on the type of contract, but at a minimum it involves developing the Terms of Reference and selecting the right candidate, then obtaining the necessary approvals and raising travel requests within GSM for deployment. At each step there are a series of approvals required at the WHO Office in the Philippines, the WHO Regional Office for the Western Pacific and sometimes at WHO headquarters. All goods and service requisitions, once approved by GSM, are processed by GSC.

We conducted a retrospective review of the GSM records for procurement, staff and consultants hired from January 2013 to December 2014 as well as assessing the lessons learnt based on our shared experiences.

\footnotetext{
Office of the WHO Representative in the Philippines, Sta Cruz, Manila, Philippines. Submitted: 17 September 2015; Published: 6 November 2015

doi: 10.5365/wpsar.2015.6.3.HYN_023
} 


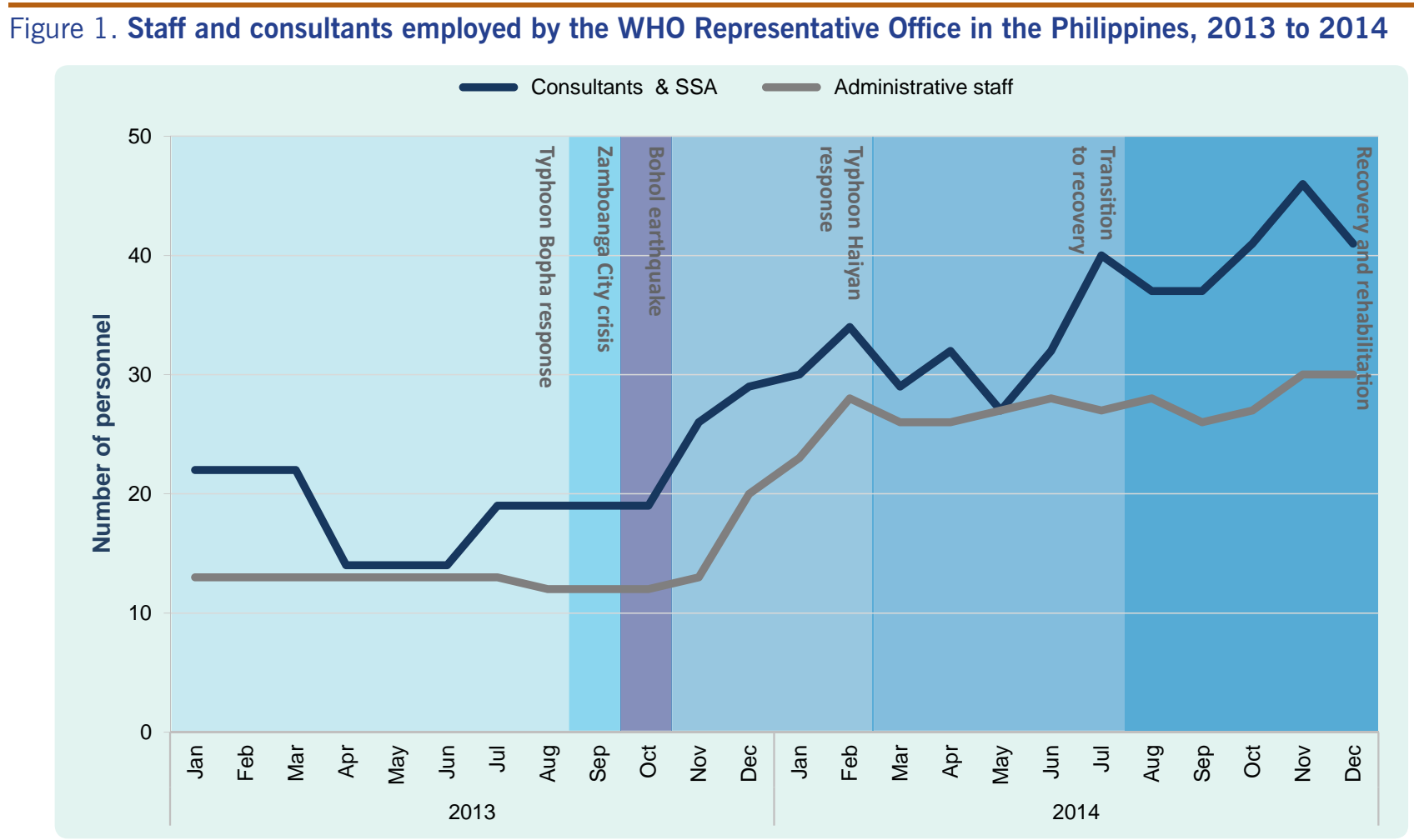

SSA, special services agreement.

Our review was for the period that corresponded to Typhoon Bopha, the Zamboanga City crisis, the Bohol earthquake and Typhoon Haiyan. Staff was defined as a short- or long-term staff member of WHO, while consultants were defined as outsiders working for WHO in a consultative capacity.

\section{RESULTS}

There were no additional staff or consultants hired during the Bopha and Bohol responses. The increased workload was handled by existing staff in the WHO Representative Office in the Philippines, usually by working longer hours. All other core technical programmes e.g. immunization and malaria, continued as usual. One staff member was deployed to Bohol to support consultants and staff already on the ground. During the Zamboanga response a local suboffice was setup and managed by two newly recruited staff, an existing staff member and a driver.

By contrast, within days of Haiyan's landfall in November 2013, additional staff from across all levels of WHO assisted the WHO Representative Office in the Philippines, including administrative staff from various technical divisions of the Western Pacific Regional Office. From November 2013 to January 2015, the number of administrative and support staff at the WHO
Representative Office in the Philippines increased from 13 to 30 , and 106 international consultants were contracted. These consultants included logisticians, experts in relief operations, supply chain specialists, epidemiologists, trauma care experts and more. National consultants were also recruited. Furthermore, seven suboffices were established throughout the affected areas.

The number of international and national consultants decreased into 2014. However, the number of national consultants increased to continue recovery operations with a focus on capacity-building and sustainability (Figure 1).

The work required to recruit and deploy both international and national consultants was enormous. To enhance administrative capacity, the WHO Representative Office in the Philippines increased the number of staff (Figure 1). Requests submitted through GSM for the response to Haiyan were estimated to be in the tens of thousands.

The WHO Representative Office in the Philippines spent approximately 22 times its annual budget during the Typhoon Haiyan response. Almost US\$ 23 million worth of goods and services were procured over 
Figure 2. Medicine and equipment spending by the WHO Representative Office in the Philippines, 2013 to 2014

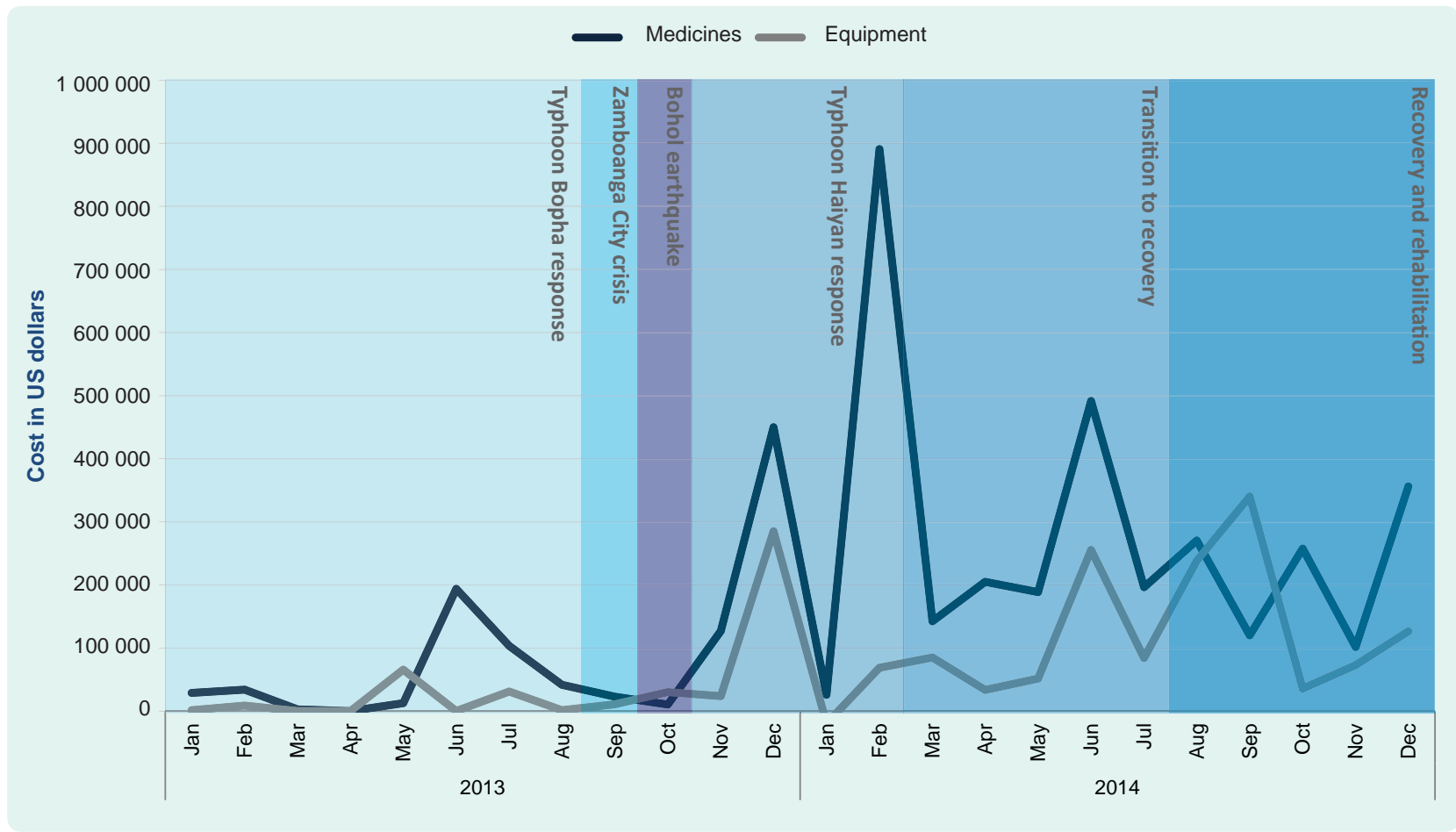

12 months. Medicine and equipment procurement peaked in February 2014 when approximately US\$ 900000 was spent. (Figure 2).

The large number of requests processed through GSM during the response highlighted that the normative system was not flexible enough to cope with the increased demand of a large-scale disaster response. The process of approvals could not be changed in the system and required several levels of approval from staff who were mostly deployed in the field (with limited internet access) and involved in various aspects of the response. Also, regardless of the type of request, the system required approval by the WHO Representative of the Philippines.

\section{DISCUSSION}

Compared with the business-as-usual response to the three preceding disasters in 2013, the work of the administrative team for the response to Typhoon Haiyan was unprecedented. Disasters will continue to occur in the Philippines, and the WHO Office in the Philippines will continue to support the $\mathrm{DOH}$. This paper has shown the magnitude of the response for logistics procurement and personnel recruitment. The experience has also shown that the administration team can react and adapt during a large-scale response although there are multiple aspects that can be addressed to improve responsiveness.

We recommend creating an administrative organogram and toolkit with an organizational shift that activates during emergency situations to address these issues. Furthermore, the flexibility of system approvals must be reviewed and improved to facilitate the response to a disaster of such magnitude. As a result of lessons learnt during Haiyan, the WHO Representative Office of the Philippines has created an ERF toolkit with administrative templates and procedures under core services that were implemented during the period to help facilitate future emergency responses.

\section{Conflicts of interest}

None declared.

\section{Funding}

None. 


\section{Acknowledgements}

We thank all staff from the WHO Representative Office in the Philippines who put in so much work and heart during the response and recovery for Typhoon Haiyan. We would also like to thank $\mathrm{Dr}$ Allison Gocotano, Mr Rommel Millora, Ms Laarni Garcia, Ms Diana Go-Ordinario and Mr Sherif Younan for the guidance and providing data for this report.

\section{References}

1. Gocotano A et al. Can you help me write my story? The institutional affiliations of authors of international journal articles on post-disaster health response. Western Pacific Surveillance and Response Journal, 2015, 6(Suppl 1):10-14. doi:10.5365/ wpsar.2015.6.3.HYN_019

2. Annual tropical cyclone tracks. Quezon City, Phillippine Atmospheric, Geophysical and Astronomical Services Administration (PAGASA), 2015 (http://www.pagasa.dost.gov.ph/ index.php/25-tropical-cyclones/33-annual-tropical-cyclone-tracks, accessed 9 October 2015).

3. Emergency response framework (ERF). Geneva, World Health Organization, 2013 (http://www.who.int/hac/about/erf .pdf, accessed 9 October 2015).
4. Typhoon Yolanda (Haiyan) Philippines, Situation Report No. 2 (17 November 2013). Manila, World Health Organization Emergency Support Team, 2013 (http://www.wpro.who.int philippines/typhoon_haiyan/media/Sitrep_17Nov2013.pdf?ua=1, accessed 9 October 2015).

5. The Government of the Philippines. NDRRMC Update SitRep No. 35 re effects of magnitude 7.2 Sagbayan, Bohol Earthquake. New York, ReliefWeb, 2013 (http://reliefweb.int/report/philippines/ ndrrmc-update-sitrep-no-35-re-effects-magnitude-72-sagbayanbohol-earthquake, accessed 9 October 2015).

6. International Organization for Migration. Zamboanga Crisis: Situation Report No. 114, 14 October 2013. New York, ReliefWeb, 2013 (http://reliefweb.int/sites/reliefweb.int/files/resources/IOMPhilippines-in-Zamboanga-Crisis-Response-Update-20131014. pdf, accessed 9 October 2015).

7. Lew W, Zagaria N, Diaz-Herrera C. Response to the crisis caused by Typhoon Bopha in the Philippines-14 December 2012. Manila, WHO in the Philippines, 2012 (http://www.who.int/ hac/donorinfo/WHOdonor_alert_philippines_14dec2012.pdf, accessed 9 October 2015).

8. Typhoon Bopha - Dec 2012. New York, ReliefWeb, 2012 (http://reliefweb.int/disaster/tc-2012-000197-phl, accessed 9 October 2015).

9. Posta I, Zahran M. Review of management, administration and decentralization in the World Health Organization. Geneva, World Health Organization, 2012 (https://www.unjiu.org/en/ reports-notes/JIU\%20Products/JIU_REP_2012_6_English.pdf, accessed 9 October 2015). 